\title{
Reversal of Neurofibrillary Tangles and Tau-Associated Phenotype in the rTgTauEC Model of Early Alzheimer's Disease
}

\author{
Manuela Polydoro, ${ }^{1}$ Alix de Calignon, ${ }^{1}$ Marc Suárez-Calvet, ${ }^{1,2}$ Laura Sanchez, ${ }^{1}$ Kevin R. Kay, ${ }^{1}$ Samantha B. Nicholls, ${ }^{1}$ \\ Allyson D. Roe, ${ }^{1}$ Rose Pitstick, ${ }^{3}$ George A. Carlson, ${ }^{3}$ Teresa Gómez-Isla, ${ }^{1,2}$ Tara L. Spires-Jones, ${ }^{1}$ and Bradley T. Hyman ${ }^{1}$ \\ ${ }^{1}$ MassGeneral Institute for Neurodegenerative Disease, Department of Neurology, Alzheimer's Disease Research Laboratory, Massachusetts General \\ Hospital, Harvard Medical School, Charlestown, Massachusetts 02129, ${ }^{2}$ Neurology Department, Hospital de la Santa Creu i Sant Pau, Universitat Autònoma \\ de Barcelona, Barcelona, 08025, Spain, and ${ }^{3}$ McLaughlin Research Institute, Great Falls, Montana 59405
}

Neurofibrillary tangles (NFTs), a marker of neuronal alterations in Alzheimer's disease (AD) and other tauopathies, are comprised of aggregates of hyperphosphorylated tau protein. We recently studied the formation of NFTs in the entorhinal cortex (EC) and their subsequent propagation through neural circuits in the rTgTauEC mouse model (de Calignon et al., 2012). We now examine the consequences of suppressing transgene expression with doxycycline on the NFT-associated pathological features of neuronal system deafferentation, NFT progression and propagation, and neuronal loss. At 21 months of age we observe that EC axonal lesions are associated with an abnormal sprouting response of acetylcholinesterase (AChE)-positive fibers, a phenotype reminiscent of human AD. At 24 months, NFTs progress, tau inclusions propagate to the dentate gyrus, and neuronal loss is evident. Suppression of the transgene expression from 18 to 24 months led to reversal of AChE sprouting, resolution of Gallyas-positive and Alz50-positive NFTs, and abrogation of progressive neuronal loss. These data suggest that propagation of NFTs, as well as some of the neural system consequences of NFTs, can be reversed in an animal model of NFT-associated toxicity, providing proof in principle that these lesions can be halted, even in established disease.

\section{Introduction}

An early and prominent neuropathological lesion in human AD is neurofibrillary tangles (NFTs) in the entorhinal cortex (EC), which then extend to the hippocampus, and ultimately the neocortex (Hyman et al., 1984; Braak and Braak, 1991; Delacourte et al., 1999). Recently, three groups modeled this process taking advantage of the fortuitous observation that a line of neuropsin (kallikrein related-peptidase $8, K l k 8$ ) promoter-driven tTa mice expressed this transcriptional activator primarily in the medial EC (Yasuda and Mayford, 2006). When crossed with a responder line that expresses the P301L mutant version of human tau, restricted and controllable expression of the transgene in the medial EC was obtained (Harris et al., 2012; Liu et al., 2012; de Calignon et al., 2012). As the animals age, tau becomes mislocalized from the axons to the soma, tau-positive NFT-like aggregates form, and human tau-positive aggregates develop in downstream

Received Feb. 26, 2013; revised May 22, 2013; accepted June 16, 2013.

Author contributions: M.P., T.L.S.-J., and B.T.H. designed research; M.P., A.d.C., M.S.-C., L.S., K.R.K., A.D.R., R.P., G.A.C., T.G.-I., and T.L.S.-J. performed research; M.P., A.d.C., M.S.-C., and T.L.S.-J. analyzed data; M.P. and S.B.N. wrote the paper.

This work was supported by NIH Grants R00AG033670, R01AG026249-07, T32AG00022222, and the Alzheimer's Association Zenith Award ZEN-09-132524. We thank Mark Mayford for providing neuropsin-tTA mice, Peter Davies for providing tau antibodies, and Robert Koffie for his technical support.

The authors declare no competing financial interests.

Correspondence should be addressed to Dr. Bradley T. Hyman, Massachusetts General Hospital, Department of Neurology, Alzheimer's Disease Research Laboratory, 114 16th Street, Room 2009, Charlestown, MA 02129. E-mail: bhyman@partners.org.

DOI:10.1523/JNEUROSCI.0881-13.2013

Copyright $\odot 2013$ the authors $\quad 0270-6474 / 13 / 3313300-12 \$ 15.00 / 0$ targets of the EC. We showed by in situ hybridization and by laser capture microdissection and qRT-PCR that tau mRNA is not detectable in the dentate gyrus neurons that are human tau protein-positive and RNA-negative, suggestive of a transsynaptic propagation of tau (de Calignon et al., 2012). These results show that tau overexpression in the EC led to damage of its major efferent projection to the dentate gyrus (DG), the perforant pathway. Damage of this neural system in patients is thought to underlie memory impairment in AD (Hyman et al., 1984; Gómez-Isla et al., 1996), and to be the first stage of what has been considered to be an irreversible cascade of lesions leading ultimately to widespread damage and dementia.

Taking advantage of the restricted pattern of expression, well defined anatomy, and the suppressible nature of transgene expression in the rTgTauEC line, we now studied the consequences of prolonged expression of the transgene, and asked whether, and to what extent, the damage caused could be reversed by suppressing tau overexpression. Remarkably, we found that extended transgene suppression for 6 months reverses many of the transgene-associated phenotypes, including Gallyas-positive NFTs, and stops neuronal loss, providing proof in principle that these lesions could be halted, even in established disease.

\section{Materials and Methods}

Animals

rTgTauEC mice. We generated transgenic animals (called rTgTauECfor reversible tau restricted to entorhinal cortex) by crossing FVB$\mathrm{Tg}\left(\right.$ tetO-Tau $\left.\mathrm{P} 301 \mathrm{~L}_{\mathrm{L}}\right) 4510$ mice (Santacruz et al., 2005) with a transgenic 
mouse line on a C57BL/6 genetic background expressing tet transactivator under the control of the Klk8 neuropsin promoter (EC-tTa) that was developed at the Scripps Research Institute (Yasuda and Mayford, 2006). F1 offspring were used as experimental animals ensuring a uniform 50:50 mix of FVB and C57BL/6 genetic background. Inheritance of both the responder and activator transgenes (designated rTgTauEC) results in P301L mutant tau expression restricted to layer II of the EC and presubiculum and parasubiculum (de Calignon et al., 2012). Age-matched littermates expressing only the activator transgene were used as human tau-negative controls. rTgTauEC and control mice were identified by PCR screening using the primer pairs $5^{\prime}$-ACCTGGACATGCTGTGATAA- $3^{\prime}$ and $5^{\prime}$ TGCTCCCATTCATCAGTTCC- $3^{\prime}$ for activator transgenes, and $5^{\prime}$ TGAACCAGGATGGCTGAG CC-3' and 5'-TTGTCATCGCTTCCAGTC CCCG-3' for responder transgenes. Each of the different age groups studied $(3,18,21,24$ months) contained transgenic and control animals of either sex. Three groups of animals were treated with doxycycline (dox; 200 ppm in chow ad libitum) to suppress the transgene expression: 18-month-old mice were treated for 3 months or 6 months, and 21-month-old mice were treated for 3 months.

EC-tdTomato/Syp-GFP mice. Mice expressing a tetracycline transactivator under the neuropsin promoter (EC-tTa) (Yasuda and Mayford, 2006) were crossed with $\mathrm{Tg}$ (tetO-tdTomato,-Syp/mut4EGFP)1.1Luo/J (obtained from Jackson Laboratory) expressing Myc-tagged tdTomato and full-length mouse synaptophysin/mut4EGFP fusion protein (SypGFP) expression under the control of the bidirectional tet-responsive promoter (tetO or TRE) (Li et al., 2010; Miyamichi et al., 2011). tdTomato expression is cytoplasmic, marking the entire cell, while GFP expression is directed to the synapse/synaptic vesicle.

All animal experiments were performed under United States National Institutes of Health guidelines and were reviewed and approved by the Institutional Animal Care and Use Committees of Massachusetts General Hospital and McLaughlin Research Institute.

\section{Western blot analysis}

Dissected EC were homogenized in RIPA buffer (Invitrogen) supplemented with a mixture of protease and phosphatase inhibitors (Roche). Samples were homogenized using a Polytron and the protein content was determined by BCA protein assay (Thermo Scientific). The materials for SDS-PAGE were obtained from Invitrogen (NuPAGE system). Protein lysates were boiled in sample buffer consisting of lithium dodecyl sulfate sample buffer and reducing agent and resolved on $4 \%-12 \%$ Bis-Tris polyacrylamide precast gels in MES SDS running buffer. Thirty milligrams of protein were loaded per lane; proteins were transferred onto nitrocellulose membranes Protran (Whatman) in transfer buffer containing 20\% methanol. Blots were blocked in Odyssey blocking buffer (Li-Cor Biosciences), followed by incubation with primary antibodies [ $\beta$-actin (mouse monoclonal antibody, Sigma; $1: 10,000$ ), HT7 (mouse monoclonal antibody, Thermo Scientific; 1:5000)], and detected with anti-mouse or anti-rabbit IgG conjugated to IRDye 680 or 800 (Li-Cor Biosciences; 1:10,000). Densitometric and molecular weight analyses were performed using ImageJ software (National Institutes of Health). Band density values were normalized to $\beta$-actin levels. Mean band densities for samples from rTgTauEC mice were normalized to corresponding samples from 24-month-old mice that did not receive doxycycline treatment.

\section{Real-time quantitative RT-PCR}

Total RNA was extracted by homogenizing tissue in $500 \mu \mathrm{l}$ of Trizol reagent (Invitrogen) followed by addition of $100 \mu \mathrm{l}$ of chloroform at room temperature and incubated for $10 \mathrm{~min}$. Samples were centrifuged for $15 \mathrm{~min}$ at $12,000 \times \mathrm{g}$ at $4^{\circ} \mathrm{C}$ and the aqueous phase was transferred to new, RNase-free Eppendorf tubes. The RNA was precipitated by addition of $250 \mu \mathrm{l}$ of isopropanol and frozen for $1 \mathrm{~h}$ at $-80^{\circ} \mathrm{C}$. These samples were then centrifuged for $15 \mathrm{~min}$ at $12,000 \times g$ at $4^{\circ} \mathrm{C}$, the RNA pellets were washed in $70 \% \mathrm{EtOH}$, air-dried for several minutes, and then suspended in $14 \mu \mathrm{l}$ of UltraPure DNase/RNase-Free Distilled Water. RNA samples were assayed for quality with an Agilent 6000 Bioanalyzer and a Nanodrop spectrophotometer. Reverse transcription was performed on all RNA samples (Superscript II, Invitrogen) and random hexamers. qPCR analysis (on Bio-Rad iCycler) of the cDNA product was performed using primers against the transgenic human tau construct (5-CCC AAT CAC TGC CTATAC CC-3 and 5-CCA CGA GAA TGC GAA GGA-3), mouse tau exon 7 (5-AGC CCT AAG ACT CCT CCA-3 and 5-TGC TGT AGC CGC TTC GTTCT-3). Duplicates of cDNA samples were added to a $25 \mu \mathrm{l}$ reaction containing $12.5 \mu \mathrm{l}$ of SYBR Green Master Mix (Applied Biotechnology). For the standard curve, we subcloned cDNA amplicons generated using the qPCR primers in the pcDNA 3.1 vector system (Invitrogen) according to the manufacturer's instructions. After verifying the respective specificities of the cDNA clones by sequencing, these were used to generate individual standard curves, thus allowing for calculation of molarity and number of mRNA molecules in the samples. Finally, the respective transgenic tau mRNA levels were normalized to murine tau mRNA levels.

\section{Immunohistochemistry}

Standard immunofluorescence techniques were used. Briefly, animals were killed by $\mathrm{CO}_{2}$ inhalation and brains were fixed in $4 \%$ paraformaldehyde with $15 \%$ glycerol cryoprotectant for $48 \mathrm{~h}$. Horizontal floating sections throughout the entire brain were cut at 40 or $50 \mu \mathrm{m}$. Endogenous peroxidase activity was quenched for $30 \mathrm{~min}$ in $\mathrm{H}_{2} \mathrm{O}_{2}$ and sections permeabilized by $20 \mathrm{~min}$ incubation in $0.1 \%$ Triton X-100 solution. After blocking in 5\% normal goat serum (NGS) for $1 \mathrm{~h}$, the appropriate primary antibody was applied in 5\% NGS, and sections were incubated overnight at $4^{\circ} \mathrm{C}$. The antibody 5A6 antibody (1:1000) (courtesy of Dr. G.V. Johnson, University of Rochester, Rochester, NY), a monoclonal antibody raised against the longest form of recombinant human tau that recognizes an epitope between amino acids 19 and 46 (Johnson et al., 1997) was used to detect human tau; HT7 (1:1000) was used to specifically detect human tau; the conformation-specific Alz50 antibody (courtesy of Peter Davies, Albert Einstein College of Medicine, Bronx, NY; 1:50) was used to detect misfolded tau; and CP13 (pSer202) and PHF1 (pSer396/404) (courtesy Peter Davies, Albert Einstein College of Medicine; 1:500) were used to detect phospho-tau. GFP antibody (BD Biosciences; $1: 1000$ ) was used to reveal Syp-GFP fusion protein. Sections were subsequently washed in TBS to remove excess primary antibody. Sections were incubated in the appropriate secondary antibody in 5\% NGS for $1 \mathrm{~h}$ at room temperature. For immunofluorescence, Fluorescent Alexa Fluor 488 (Invitrogen) or CY3-labeled secondary antibodies (Jackson ImmunoResearch) were used to reveal primary antibodies; or horseradish peroxidase $(\mathrm{HRP})$-conjugated secondary antibodies were used and developed with diaminobenzidine (DAB) substrate by using the avidinbiotin horseradish peroxidase system (Vector Laboratories).

\section{Gallyas silver staining}

Staining was performed on brain sections according to previous description (Gallyas, 1971). Briefly, free-floating brain sections were incubated in a $0.003 \%$ potassium permanganate solution for $10 \mathrm{~min}$. After rinsing with water the sections were incubated for $1-2 \mathrm{~min}$ in a $2.0 \%$ oxalic acid solution, then rinsed thoroughly in water. Sections were then incubated in a $5.0 \%$ sodium metaperiodate solution for $5 \mathrm{~min}$ and again rinsed in water. Sections were then treated with an alkaline silver iodide solution (1 M sodium hydroxide, $0.6 \mathrm{M}$ potassium iodide, $0.053 \%$ silver nitrate) for 1 $\mathrm{min}$, then rinsed four times with a $0.5 \%$ acetic acid solution. Staining was developed by combining solutions A ( $5 \%$ sodium carbonate), B $(0.024 \mathrm{M}$ ammonium nitrate, $0.012 \mathrm{M}$ silver nitrate, $0.003 \mathrm{M}$ tungstosilicic acid), and $\mathrm{C}$ ( $0.024 \mathrm{M}$ ammonium nitrate, $0.012 \mathrm{M}$ silver nitrate, $0.003 \mathrm{M}$ Tungstosilicic acid, $0.25 \%$ formaldehyde) in a 2:1:1 ratio, adding B and C dropwise to solution $A$ and incubating for $10-30 \mathrm{~min}$. The sections were then rinsed three times in $0.5 \%$ acetic acid, then water. The sections were then incubated in gold tone for 3-4 min and again rinsed in water, then in a $1 \%$ sodium thiosulphate solution for $5 \mathrm{~min}$. After a final rinse in water the sections were mounted.

\section{Stereology}

To assess the effects of transgene suppression on cholinergic innervation, neuronal loss, and the percentage of Alz50 and Gallyas-positive aggregates in the medial EC and DG, brains were collected from 24-month-old rTgTauEC mice and control littermates. Subsets of mice were either aged without treatment (no transgene suppression $n=5 \mathrm{rTgTauEC}$, 4 wild- 
type) or treated with doxycycline for 3 months (from 21 to 24 months, $n=4 \mathrm{rTgTauEC}$ ) or 6 months (from 18 to 24 months, $n=4 \mathrm{rTgTauEC}$, 3 wild-type) before killing to suppress tau transgene expression. A series of every 10th horizontal section through the brain was stained for Alz50 as mentioned above. Nuclei were counterstained using cresyl violet (cv). An image analysis system (CAST, Olympus) mounted on an upright BX51 Olympus microscope with an integrated motorized stage (Prior Scientific) was used to estimate region volume, neuron density, neuron number, and whether neurons were Alz50 positive using the optical dissector method as described previously (Spires et al., 2006). Briefly, on each section, layer II of the medial EC (including both the caudal and medial portions of the medial entorhinal area) was outlined as described previously (Gatome et al., 2010). Neurons were identified by nuclear morphology as described previously (Spires et al., 2006) and counted in a $28.1 \times 28.1 \times 40 \mu \mathrm{m}$ counting frame placed using a meander sampling paradigm with a $100 \mu \mathrm{m}$ step length (to sample 100-300 neurons per animal). Coefficient of error for neuron counts in the EC of each animal was $<0.01$. Each neuron was labeled as Alz50 positive or negative. Region volumes were determined according to Cavalieri's principle and the total number of neurons in each region calculated.

Stereology data were normally distributed as assessed by ShapiroWilk's test using JMP software. To assess the effects of doxycycline treatment on neuron number in control mice, a one-way ANOVA split by genotype was used. Since there was no effect of 6 months of doxycycline treatment on control mice, all control mice (treated and untreated) were combined as the control condition and an ANOVA with condition as independent variable used to compare control to rTgTauEC untreated, rTgTauEC doxycycline treated for 3 months, and rTgTauEC dox-treated for 6 months. Post hoc Tukey-Kramer HSD tests were used to compare means of groups. A one-way ANOVA with doxycycline treatment as independent variable was used to determine the effects of transgene suppression on the percentage of Alz50-positive neurons.

\section{Quantification of the percentage of PHF1 and CP13-positive} neurons in the DG

Using the CAST stereo logy system, the DG was outlined on two sections per mouse ( $n=5$ per group). All PHF1- or CP13-positive neurons in the DG were counted, and the total number of cells in that section of DG estimated by systematic random sampling every $100 \mu \mathrm{m}$ through the DG and counting neurons in a $21.8 \times 21.8 \mu \mathrm{m}$ optical disector, calculating the density of DG neurons in the disector volumes, and multiplying the density of DG neurons by the volume of the DG in the section. The percentage PHF1- and CP13positive neurons was calculated by dividing the number of PHF1- or CP13positive neurons by the estimated total number of DG neurons in the section. The two sections from each animal were averaged for the mean value per animal. Comparisons between groups were made by Mann-Whitney test.

\section{Acetylcholinesterase histochemistry}

Cholinergic innervation was revealed by histochemical staining for acetylcholinesterase (AChE), a general marker for cholinergic fibers and noncholinergic neurons that express AChE (Levey et al., 1984; Mesulam and Geula, 1991; Aubert et al., 1994). AChE histochemistry was performed as previously described (Geneser-Jensen and Blackstad, 1971). Before incubation, brain sections mounted on the slides were brought to room temperature and air-dried for $45 \mathrm{~min}$. AChE activity was determined by incubating brain sections in a $50 \mathrm{~mm}$ acetate buffer, $\mathrm{pH} 5.5$, containing $2 \mathrm{~mm}$ acetylthiocholine iodide (substrate), $2 \mathrm{~mm}$ copper sulfate, and $10 \mathrm{~mm}$ glycine. Reactions were performed for 75-90 min at $25^{\circ} \mathrm{C}$. Following incubation, the sections were rinsed five times in distilled water and then incubated in $1.25 \%$ sodium sulfide solution in distilled water ( $\mathrm{pH} 6$, freshly prepared) for $1 \mathrm{~min}$ at $25^{\circ} \mathrm{C}$. After rinsing sections five times with distilled water, sections were transferred to a $1 \%$ silver nitrate solution in distilled water for $2 \mathrm{~min}$, and then rinsed five times with distilled water.

Images for figures were collected on an upright Olympus BX51 microscope (Olympus America).

\section{Array tomography}

Tissue from 24-month-old mice, $n=3-5$ per group, was fixed, dehydrated, and embedded in LR white resin as described previously (Micheva and Smith, 2007; Koffie et al., 2009). Ribbons of $70 \mathrm{~nm}$ serial sections were cut on an ultracut microtome (Leica) and immunostained with antibodies for synaptophysin (mouse, Abcam AB8049 lot GR835101), and secondary anti-mouse 488 (Jackson ImmunoResearch Laboratories). Nuclei were counter-stained with DAPI. Images were acquired with a Zeiss AxioImager Z2 microscope equipped with automated stage, digital camera, and array tomography automated imaging plugins in AxioVision software. A tile scan of the entire ribbon was acquired at $10 \times$ magnification, then images taken of the same place in the molecular layer of the DG on each serial section with a $63 \times 1.2 \mathrm{NA}$ oil objective. Images were aligned and stacked using custom macros in ImageJ software. Regions of interest (crops) were selected on each image stack from the middle molecular layer of the dentate gyrus from areas that did not contain any neuronal nuclei or capillaries. The synaptophysin staining in each crop volume was thresholded using the "Li" algorithm in Fiji and the number of synapses in each volume was counted using the Watershed program from the Smithlab. Synapse density was calculated as the number of synapses in each crop divided by the crop volume. An average density of synapses was calculated for each animal and the means of all animals in each genotype and treatment group compared with ANOVAs (data were normally distributed, Shapiro-Wilk's test $p>0.05$ ).

\section{Results}

In this study we used the rTgTauEC mouse line that reversibly expresses human mutant tau P301L primarily in layer II of entorhinal cortex (EC-II) (de Calignon et al., 2012). The human tau gene with the P301L mutation, placed downstream of a tetracycline-operon responsive element from the rTg4510 mice, is coexpressed with an activator transgene consisting of the tet-off open reading frame (Gossen and Bujard, 1992) that is downstream of the neuropsin promoter (Yasuda and Mayford, 2006), resulting in P301L tau expression largely restricted to a subset of neurons in the medial EC-II as well as adjacent presubiculum and parasubiculum (de Calignon et al., 2012) shown by immunohistochemistry using the human tau-specific antibody 5A6 (Fig. $1 A)$. The medial entorhinal cortex as a whole has a known projection pattern that terminates in approximately the middle third of the molecular layer of the dentate gyrus (van Groen, 2001; Witter, 2007). To examine the specific pattern of terminals associated with the subset of medial EC-II neurons driven by this promoter, we generated a reporter line in which the neuropsin promoter (EC-tTa) line was crossed with the Tg(tetO-tdTomato,-Syp/ mut4EGFP)1.1 transgenic mice (Li et al., 2010; Miyamichi et al., 2011) that express Myc-tagged tdTomato and full-length mouse synaptophysin/mut4EGFP fusion protein (Syp-GFP). Expression of these proteins is under the control of the bidirectional tet-responsive promoter (tetO or TRE). tdTomato expression is cytoplasmic, marking the entire cell, while GFP expression is directed to the synapse/synaptic vesicle. The EC-tdTomato/Syp-GFP mice show tdTomato in the cell bodies, dendrites, and axons of neurons in the medial EC-II as well as in the presubiculum and parasubiculum. The distribution of Syp-GFP shows that the terminals of these tdTomato-expressing cells are in the middle molecular layer of DG (Fig. $1 B$ ), allowing direct visualization of the pattern of expression and synaptic connections generated by the neuropsin promotor activator line.

As expected, the distribution of tdTomato shows the neurons of origin and the axons of passage of the perforant pathway, with a band of axon terminals specifically occupying the middle molecular layer of the DG. This corresponds to the patterns of tau immunoreactivity observed in young ( 3 months old) rTgTauEC line (Fig. 1A), confirming the exquisite anatomic specificity of the 
A rTgTauEC mouse

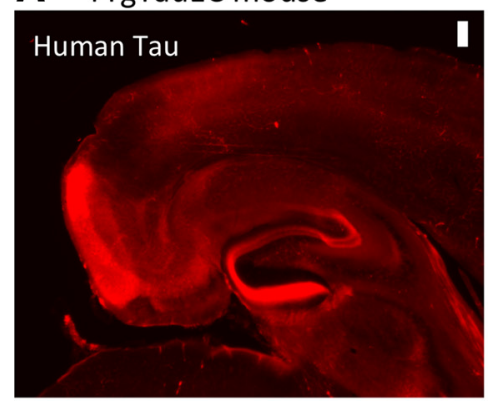

B EC-tdTomato/Syp-GFP mouse

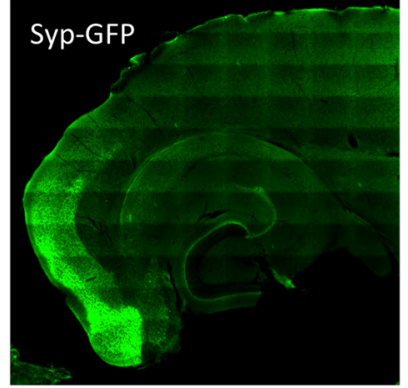

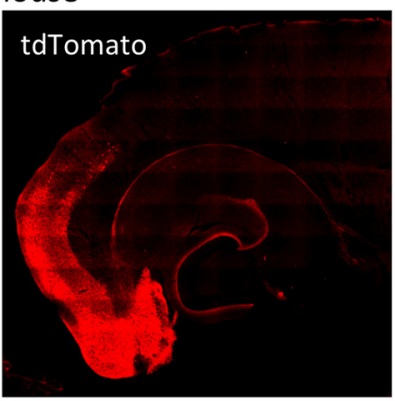

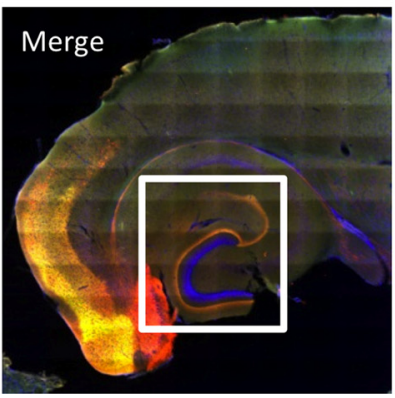

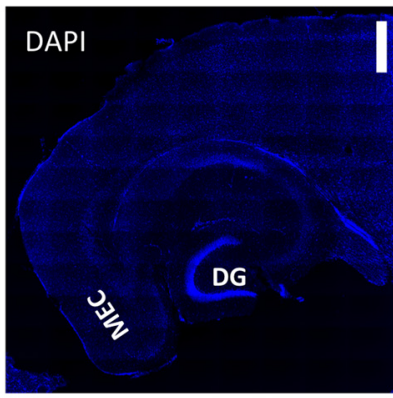

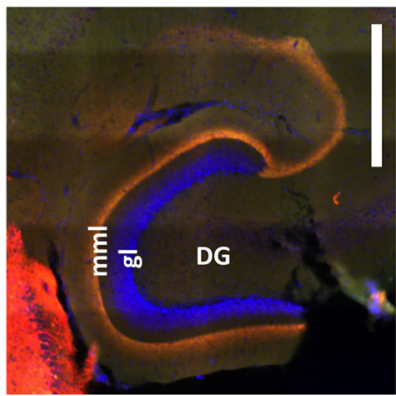

Figure 1. Expression of P301L Tau restricted to the entorhinal cortex. rTgTauEC mice express human tau in neurons of the MEC that project to the middle molecular layer (mml) of the DG via the perforant pathway. These neurons are stained with a human tau antibody in $\boldsymbol{A}$. To visualize the population of neurons expressing tau and where their synapses are located, we generated EC-tdTomato/Syp-GFP mice $(\boldsymbol{B})$, which use the same neuropsin activator transgene to restrict expression to the EC crossed with a responder that expresses both myc-tagged tdTomato (red) in the entire cell and full-length mouse synaptophysin/mut4EGFP fusion protein (Syp-GFP) that localizes to synaptic vesicles (green); nuclei are labeled with DAPI (blue). Insert shows a highermagnification image of the merged image. DG granule cells ( $\mathrm{gl}$ ) are marked by DAPI, Syn-GFP staining shows a fine discrete band in the middle molecular layer (mml) that colocalizes with the tdTomato labeling of the terminal zone of fibers from the $\mathrm{EC}$ cells (yellow). These mice confirm the expression of transgenes under this promoter is largely restricted to the $\mathrm{EC}$ and presubiculum and parasubiculum and that these neurons project axons that synapse in the middle molecular layer of the dentate gyrus. Importantly, they also confirm the absence of transgene expression in the DG granular cells Scale bars, $200 \mu \mathrm{m}$.

pattern of transgene expression driven by the neuropsin promoter. Of importance, neither human tau immunostaining nor tdTomato revealed expression in the DG granule cells (marked by DAPI in Fig. $1 B$ ), suggesting that the amount of leakiness of the tTa promoter is minimal. The distribution of synaptophysinGFP fusion protein is even more restricted, representing a fine discrete band occupying part of the middle molecular layer of the DG (Fig. $1 B$ ) as well as showing local terminals within the EC and presubiculum and parasubiculum. This pattern emphasizes the limited terminal zone of fibers from neuropsin tTa driven EC cells, and hence the area most likely to be deafferented if the tau containing terminals in the rTgTauEC line degenerate.

We confirm that doxycycline treatment suppressed transgene expression in animals at 24 months of age treated with doxycycline either from 21 months of age for 3 months or from 18 months of age for 6 months (Fig. $2 A-C$ ). Western blot analysis using a human tau-specific antibody HT7 revealed that doxycycline treatment reduced the levels of soluble human tau protein $\sim 60$ and $90 \%$ after 3 months and 6 months of treatment, respectively (Fig. 2A). The levels of human tau mRNA were quantified by qPCR and showed a reduction of $78 \%$ after 3 months and $88 \%$ after 6 months of treatment (Fig. 2B). Immunocytochemistry confirmed a marked decrease in protein levels in the entorhinal cortex following transgene suppression (Fig. 2C).

\section{Reversal of deafferentation phenotype by suppression of the tau transgene}

Classic acute deafferentation experiments in the hippocampus demonstrate a reinnervation of the deafferented perforant pathway terminal zone by sprouting of axon terminals from adjacent fields (Lynch et al., 1972), a homeostatic mechanism that pre- serves synapses. One robust response is due to AChE-positive fibers, which appear to sprout from the inner third of the DG molecular layer (their normal termination) to the deafferented portions of the DG molecular layer. We asked whether the slow, more chronic months-long process of deafferentation that plays out in the rTgTauEC line would also lead to similar plasticity and sprouting responses. We looked for aberrant sprouting of the AChE-positive fibers in the middle molecular layer of the DG.

To further evaluate the extent of apparent degeneration of the terminal zone of the perforant pathway, we quantified the degree of AChE-positive fibers sprouting into the middle molecular layer of the DG at different ages compared with the age-matched control. We observed a significant difference starting from 21 months of age that intensified at 24 months, suggesting that synaptic connections, in the area of projection of tau-expressing neurons, were altered (Fig. $3 A$ ) with resultant exuberant reinnervation by adjacent fibers.

We next evaluated the effect of transgene suppression on the sprouting of AChE fibers. Groups of mice were treated with doxycycline either from 18 months of age for 3 months $(n=4)$ or for 6 months $(n=6)$, or from 21 months of age for 3 months $(n=$ 7 ) and compared with untreated groups of equal size. Groups of age-matched control animals were similarly analyzed. When started at 18 months of age, before the initial change in AChE staining patterns, doxycycline treatment for 6 months prevented the sprouting of AChE fibers, while a shorter treatment gave an intermediate result with some animals showing decreased AChE sprouting. When started at 21 months of age, suppression of the transgene led to a normalized AChE pattern, suggesting that the AChE sprouting might not only be prevented, but also reversed by transgene suppression (Fig. $3 B, C$ ). 
A

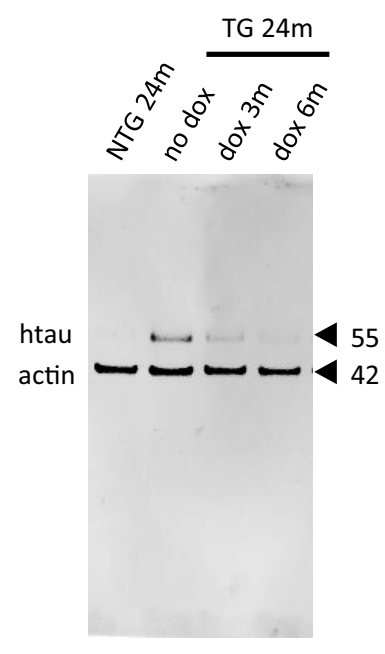

Western Blot

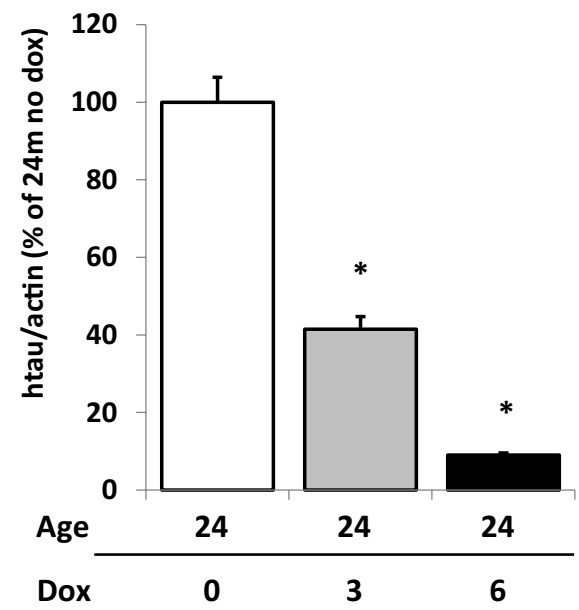

B

B $\quad$ QPCR

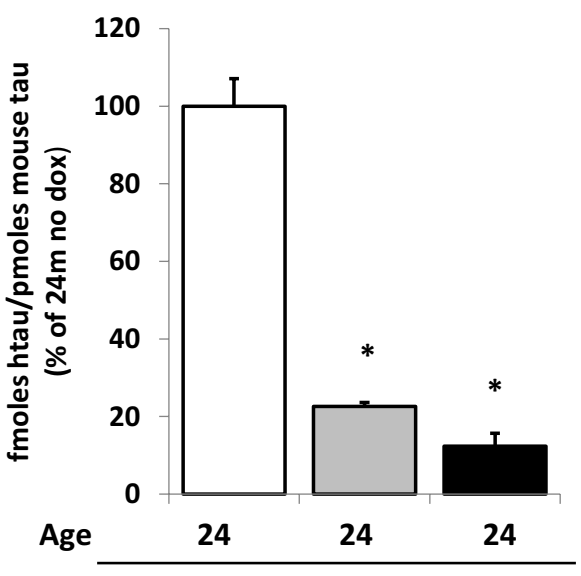

C Immunocytochemistry
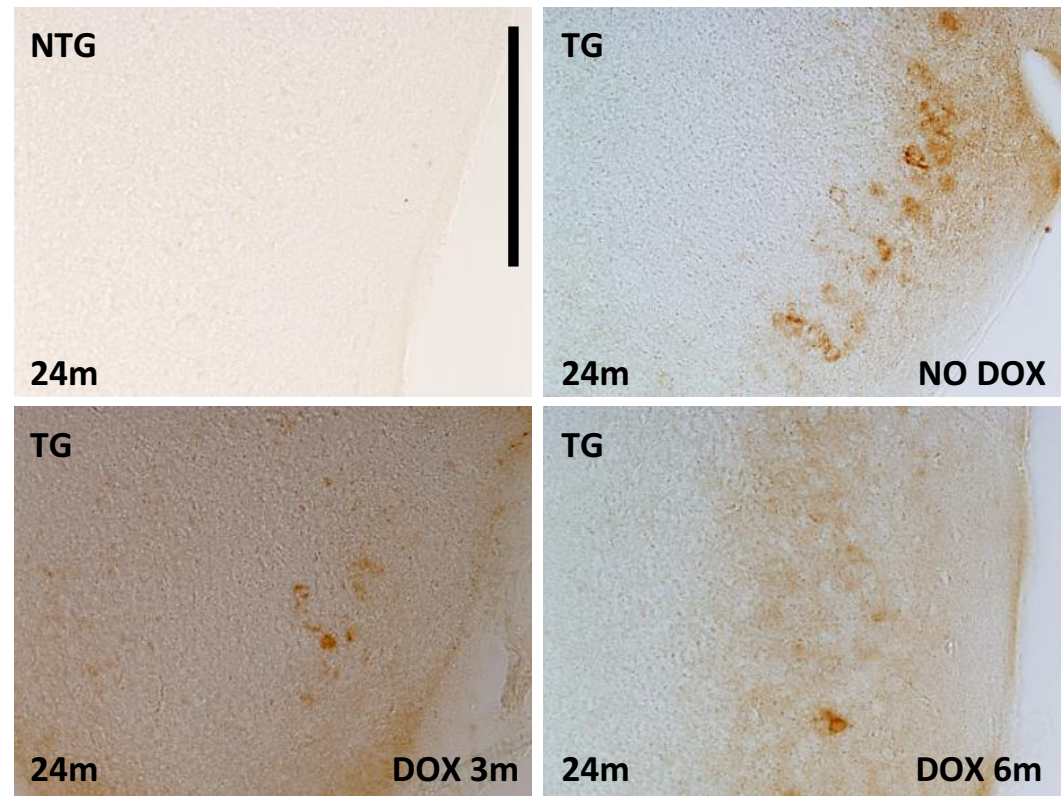

Figure 2. Tau expression in the medial entorhinal cortex is suppressed with doxycycline treatment. $\boldsymbol{A}-\boldsymbol{C}$, Doxycycline treatment suppressed transgene expression in animals at 24 months of age treated with doxycycline from 21 months of age for 3 months or from 18 months of age for 6 months. Results are labeled nontransgenic (NTG) and transgenic (TG). $A$, Western blot analysis using a human tau-specific antibody HT7 shows decreased levels of human tau protein (hTau) after 3 months and 6 months of DOX treatment. Levels of human tau protein were calculated by normalizing it to actin and are expressed as percentage of levels of hTau in 24-month-old animals that did not receive doxycycline treatment $\left(n=3\right.$ per group). ${ }^{*} p=0.005$ and $p=0.008$, respectively. $\boldsymbol{B}$, The levels of human tau RNA were quantified by qPCR and showed reduced levels of RNA. The levels of hTau RNA were calculated by normalizing it to levels of endogenous mouse tau ( $n=3$ per group) and are expressed as percentage of levels of hTau in 24 -month-old animals that did not receive doxycycline treatment. ${ }^{*} p=0.000147$ and $p=0.00000057$, respectively. C, Immunocytochemistry using HT7 confirmed a marked decrease in protein levels in the medial entorhinal cortex following transgene suppression. Scale bar, $200 \mu \mathrm{m}$. Results are expressed as the mean \pm SEM.

Suppression of the transgene prevents aggregation of tau in the entorhinal cortex and propagation of tau to dentate gyrus Human tau labeling revealed diffuse axonal staining in the middle molecular layer of the DG, which receives axons originating in the medial entorhinal cortex (MEC) of rTgTauEC (Fig. 1). This observation indicates that in young rTgTauEC mice human tau has a normal axonal distribution, similar to the physiological distribution of tau. As tau pathology progresses, human tau expression in the MEC results in age-dependent pathological changes in tau, including misfolding, hyperphosphorylation, and mislocalization to the somatodendritic compartment in EC-II transgene-expressing neurons. To quantify tau accumulation following transgene suppression, groups of mice were treated with doxycycline either from 18 months of age for 3 months $(n=4)$ or for 6 months $(n=5)$; another group was treated from 21 months of age for 3 months $(n=8)$. Groups of equal size of age-matched control animals were similarly treated. Stereological counting was performed by an investigator who was unaware of treatment status to quantify the number of Alz50-positive (misfolded tau) neurons in the EC-II after transgene suppression. Three and six months of doxycycline treatment significantly reduced the detection of Alz50-postive tau in the EC (Fig. 4A). 
A

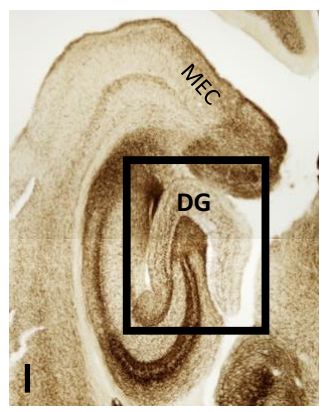

B
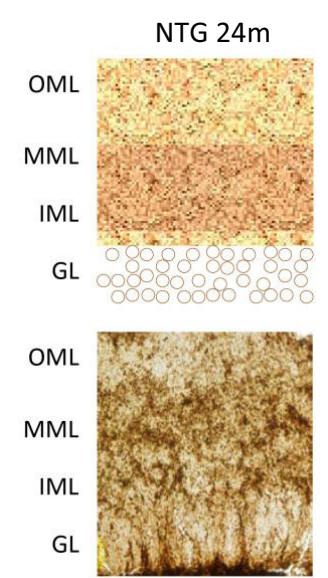

$\stackrel{\wp}{\vdash}$
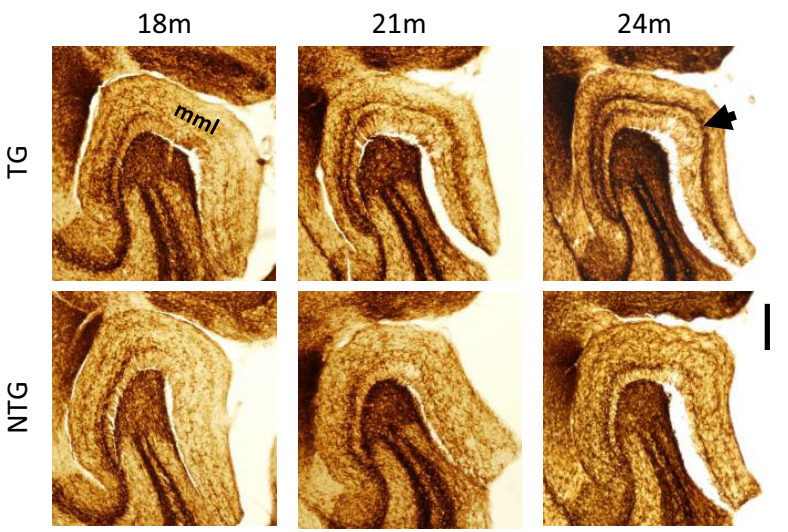

\section{C}

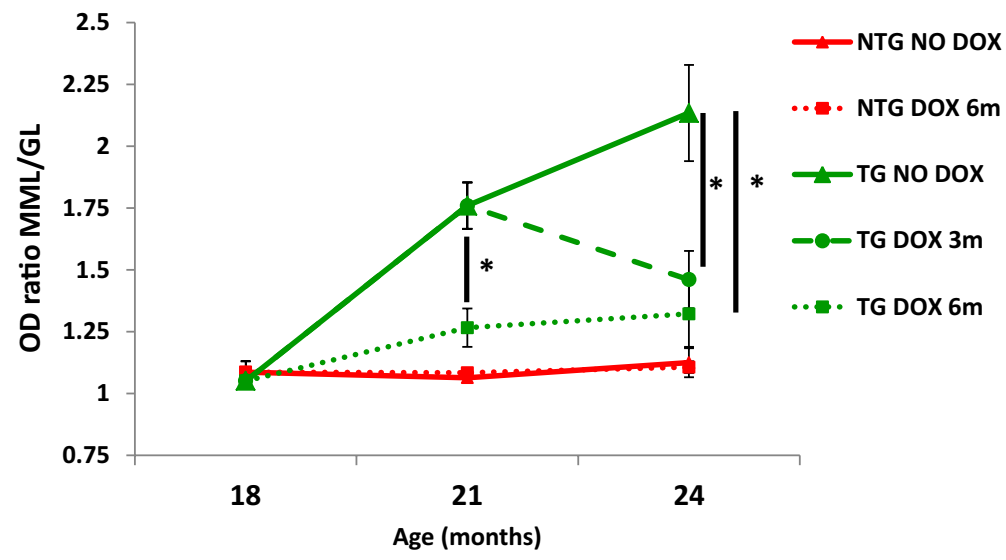

Figure 3. Reorganization of AChE fibers in the perforant pathway terminal zone. Histochemistry for AChE-positive fibers in the middle molecular layer (mml) of dentate gyrus (DG) at 18, 21, and 24 months, in rTgTauEC mice and age-matched controls shows a deafferentation-induced $A C h E$ sprouting response at 21 and 24 months ( $\boldsymbol{A}$, arrow). Images are labeled nontransgenic (NTG) and transgenic (TG). Scale bar, $200 \mu \mathrm{m}$. A, Acetylcholinesterase staining showed sprouting of axon terminals from the inner molecular layer (IML) to a thinner and denser line in the middle molecularlayer (MML). B shows a diagram representation of MEC, perforant pathway (PP), hippocampal regions CA1, CA3, and dentate gyrus (DG) with the region demarcated by black box (molecular layer) enlarged on the top left. Representative images of the molecular layer of the DG are shown on the bottom left. Scale bar, $50 \mu \mathrm{m}$. C, Comparing the ratio of optical densities between MML and IML reveals that the sprouting of AChE fibers is significant at 21 months of age and increases at 24 months, and that suppression of the transgene with a 3-month DOX treatment $(n=7)$ stops this synaptic reorganization when started at earlier age $(p=$ 0.009 ) or at later age $(p=0.01)$. A 6-month treatment $(n=6)$ was more efficient $(p=0.006)$. Results are labeled nontransgenic (NTG) and transgenic (TG). Results are expressed as the mean \pm SEM, ${ }^{*} p<0.05$.

By 18 months of age, both the rTgTauEC line and similar lines developed by the Duff laboratory (Liu et al., 2012) and by the Mucke laboratory (Harris et al., 2012) developed tau aggregates in neurons synaptically downstream from EC-II, including the
DG granule cells. These results were interpreted as propagation of tau protein into the extracellular space and uptake at postsynaptic sites. We took advantage of the ability to suppress the transgene expression using doxycycline to ask whether, once started, this process of tau protein propagation was irreversible or whether it could be intercepted by a tau-specific intervention. Doxycycline treatment was started at 18 months of age, when there is already obvious spread of tau pathology into the DG. At this age, EC terminal staining for human tau protein is fainter; with age the DG neurons become more prominently stained. At 24 months of age the transmission of the pathology is even more evident with a large number of human-tau positive aggregates in DG neurons (Fig. 4B). Human tau-positive aggregates in the DG are decreased following 3 months of transgene suppression and are almost completely blocked after 6 months of transgene suppression (Fig. 4B).

Spreading of the pathology was quantified by Alz50-positive neurons counts in the granular layer of the DG. For each brain, three sections representing the dorsal, middle, and ventral parts of the DG were quantified by an investigator who was unaware of treatment status or age. There was no change in the extent of Alz50 staining, which labels misfolded tau, in the granule cells after 3 months of doxycycline treatment. However, a longer treatment of 6 months significantly reduced the detection of Alz50-postive tau in the DG (Fig. 4C). Propagation of hyperphosphorylated tau to the DG was accessed by CP13 antibody against pSer202, an early tau pathology marker, and PHF1 that recognizes pSer396/404 (PHF tau), a marker of neurofibrillary tangles. The number of neurons labeled with both phospho-tau antibodies were markedly reduced by 3 and 6 months of tau suppression. Both markers were quantified and calculated as the percentage of cresyl violet granule cells in the DG labeled with the phospho-tau antibodies. While there were no significant differences, CP13 staining decreased $\sim 28 \%$ and PHF1 staining showed a $49 \%$ decrease after 3 months of transgene suppression. There was a trend toward reduction in $\mathrm{CP} 13(\sim 73 \%, p=$ $0.1)$ and PHF1 $(\sim 72 \%)$ staining by 6 months of tau suppression $(p=0.1$ and $p=0.07$, respectively). This experiment was not powered to detect a statistical difference with the small sample size available ( $n=5$ mice, 2 sections per mouse; Fig. 5). Nonetheless, when considered with the results of the Gallyas staining, these data are consistent with the idea that the ab- 
A Alz50 in the Entorhinal Cortex (EC)
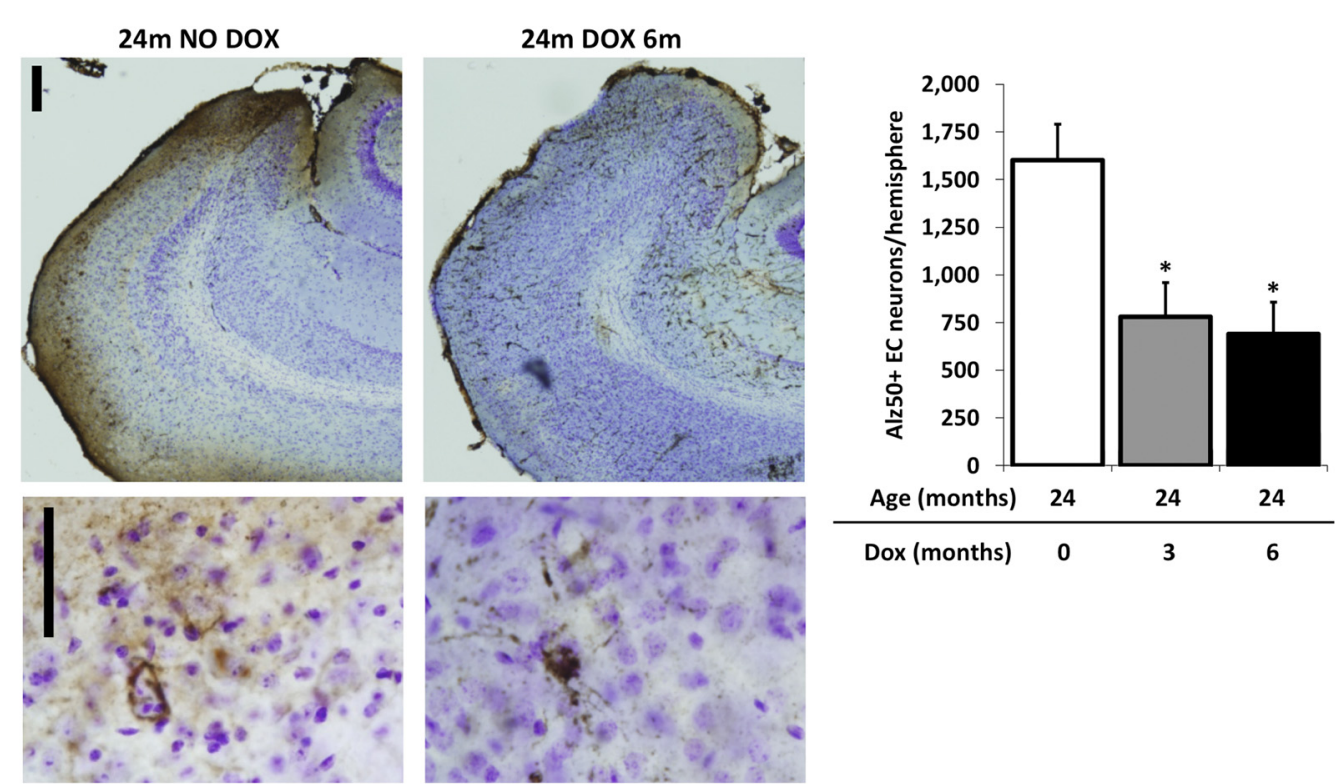

B Human Tau in the Dentate Gyrus

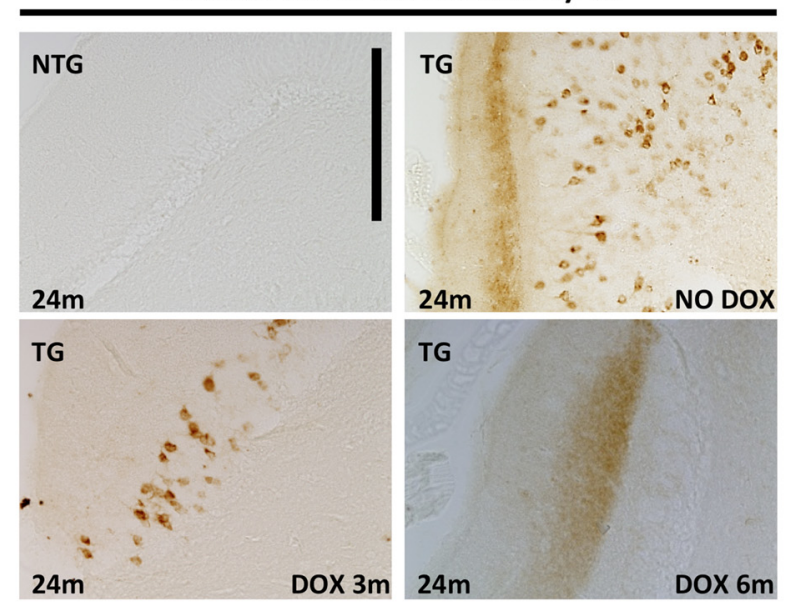

c

\section{Alz50 in the Dentate Gyrus (DG)}
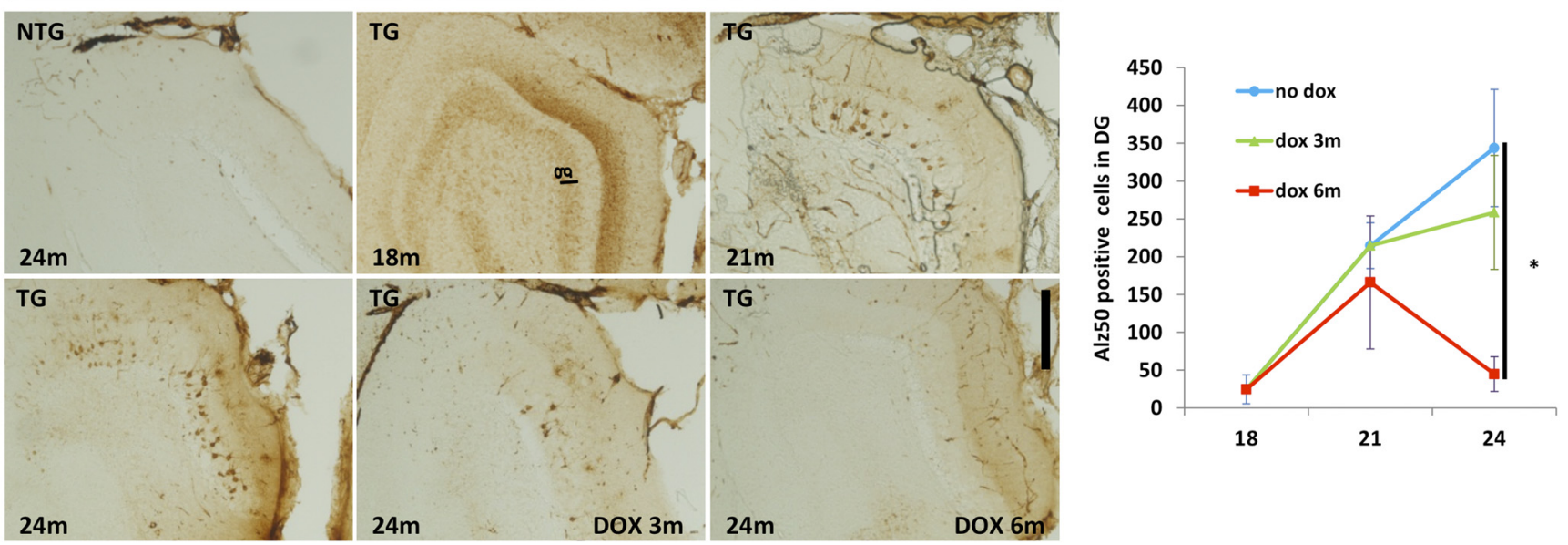

Figure 4. Transgene suppression reduces tau aggregation and propagation down neural circuits. A, Stereological counting of Alz50-positive neurons in the EC-II after transgene suppression shows that 3 and 6 months of DOX treatment significantly reduced the detection of Alz50-postive tau in the EC. This indicates that aggregation of misfolded tau in the entorhinal cortex is also prevented by $3(p=0.01751)$ and 6 months ( $p=0.00973)$ of tau suppression. $B$, Higher magnification of these sections stained with Alz50 and cresyl violet illustrate the dense, punctate staining of misfolded tau in 24-month-old transgenic animals without DOX treatment, which is reduced with tau suppression. C, Immunocytochemistry using HT7 human tau-specific antibody shows a marked decrease in propagation of human tau protein to the dentate gyrus granular cells in animals at 24 months of age treated with doxycycline from 21 months of age (Figure legend continues.) 


\section{CP13}
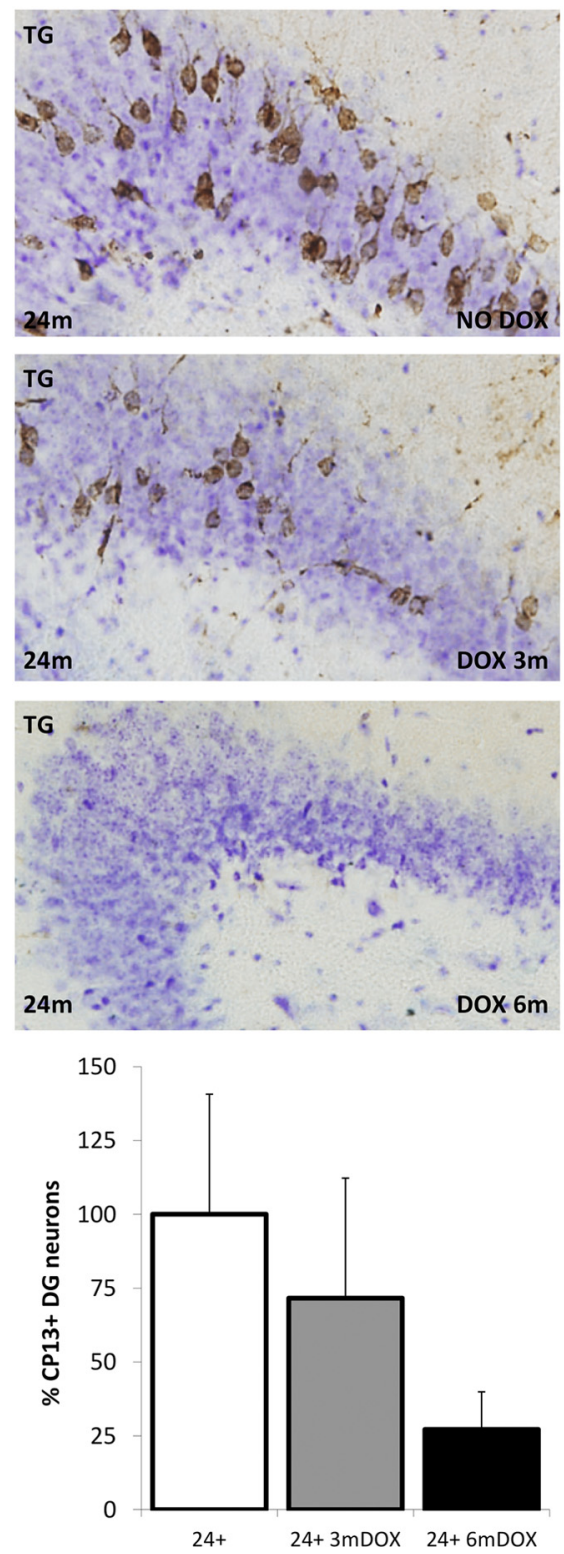

PHF1
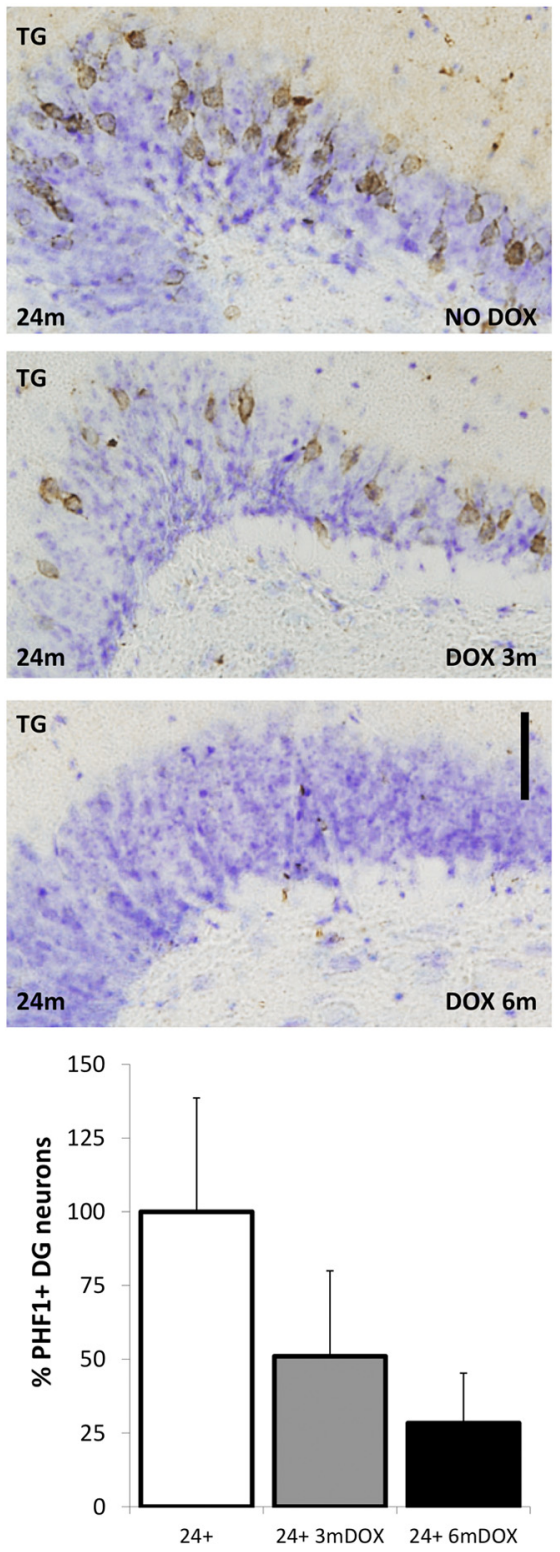

Figure 5. Propagation of hyperphosphorylated tau to the dentate gyrus after 3 and 6 months of tau suppression. Propagation of hyperphosphorylated tau to the DG was assessed by CP13 (antibody against pSer202) and PHF1 (antibody against pSer396/404; PHF tau). There was no significant difference in the number of neurons labeled with CP13 by 3 months $(n=5 ; p=0.26)$ and a slight trend toward reduction by 6 months $(n=5 ; p=0.10)$ of tau suppression compared with 24-month untreated mice $(n=$ 5). Similar results were observed for PHF1 with no significant changes by 3 months $(n=5 ; p=0.14)$ and a slight trend toward reduction by 6 months $(n=5 ; p=0.07)$ of tau suppression compared with 24-month untreated mice $(n=5)$. Sections were also stained with crystal violet. Images are labeled nontransgenic (NTG) and transgenic (TG). Results are expressed as the mean \pm SEM, ${ }^{*} p<0.05$. Scale bar, $50 \mu \mathrm{m}$.

(Figure legend continued.) for 3 months or from 18 months of age for 6 months. Spreading of tau pathology was quantified by Alz50-positive neuron counts in the granular layer $(\mathrm{gl})$ of dentate gyrus (DG). Different groups of mice were treated with DOX either from 18 months of age for 3 months $(n=4)$ or for 6 months $(n=5)$; another group was treated from 21 months of age for 3 months $(n=8)$. No change in the extent of misfolded tau in the granule cells was evident after 3 months of doxycycline treatment. Longer treatment ( 6 months), however, significantly reduced the detection of human tau in the $D G$, showing that propagation of tau pathology to the dentate gyrus is reversed by 6 months of tau suppression $(p=0.005154)$. Images are labeled nontransgenic (NTG) and transgenic (TG). Scale bar, $200 \mu \mathrm{m}$. Results are expressed as the mean \pm SEM, ${ }^{*} p<0.05$. sence of granule cell and EC pathology was due to the turn-over of existing aggregated mutant human tau protein after prolonged transgene suppression.

Tangles, visualized by Gallyas silver staining, are reversed by 6 months of tau suppression

The reduction of misfolded tau, a pretangle marker as well as hyperphosphorylated PHF tau, led us to ask whether tangles had been cleared from the EC as suggested by the decrease in PHF-1 staining, a known moderate to late stage marker of pathological change. We next evaluated the effect of transgene suppression on the progression of neurofibrillary tangles as assessed by silver staining in the EC. Silver-positive tangles are generally believed to be insoluble, long-lived lesions (Sun et al., 2002; Kertesz et al., 2005; Lee et al., 2010; Braak et al., 2011). We quantified the number of Gallyas-positive neurons after transgene suppression in the EC-II and found that 6 months of doxycycline treatment significantly reduced the detection of Gallyas-positive neurons in the EC (Fig. 6).

All of the markers of tau pathology tested, Alz50 (Fig. 4), pSer202, pSer396/404 (Fig. 5), and Gallyas (Fig. 6), seem to be either ameliorated or reversed in parallel.

\section{Synaptic loss in the target zone of the perforant pathway and neuronal loss is prevented by transgene suppression} Synapse loss is an early AD hallmark and it strongly correlates with cognitive impairment (DeKosky and Scheff, 1990; Terry et al., 1991; Scheff and Price, 2006). We have previously shown that rTgTauEC mice have synapse loss at 24 months of age in the middle molecular layer of the DG, indicating loss of synapses between EC-II neurons and DG neurons (de Calignon et al., 2012). To assess whether transgene suppression can improve synapse loss, we used array tomography to allow highresolution quantitative measurement of synaptic densities in the perforant pathway terminal zone of rTgTauEC mice after doxycycline treatment. Array tomography analysis using synaptophysin reveals a significant $16 \%$ decrease in presynaptic bouton density in the middle molecular layer of 24-month-old rTgTauEC mice. After 3 or 6 month transgene suppression (Fig. $7 A$ ), synapse density in the middle molecular layer was not different from controls.

We have previously shown that rTgTauEC mice have significant neuronal loss at 24 months of age, in the areas of robust transgene expression, EC-II and parasubiculum. The striking clearance of Gallyas-positive NFTs could be explained by either turnover or clearance of the misfolded human tau making up the aggregates, or progressive loss of NFT-bearing neurons. The lat- 


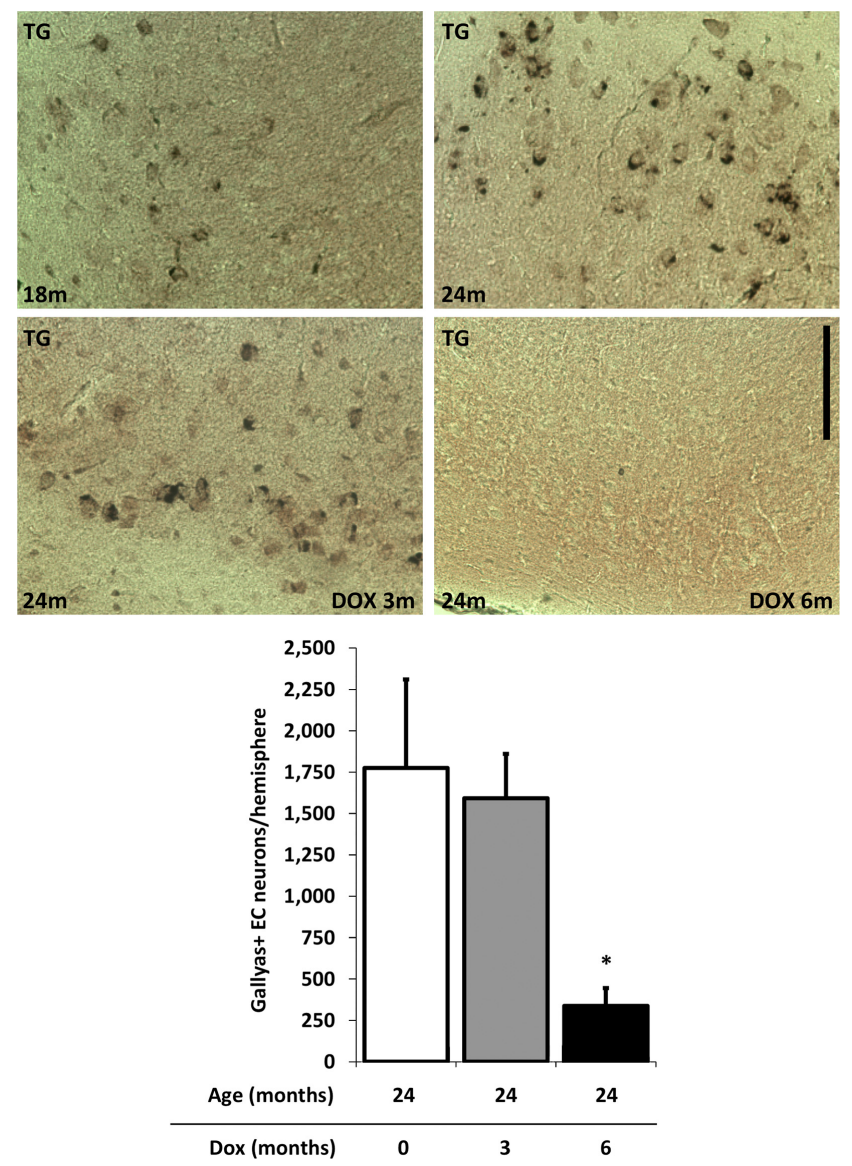

Figure 6. Tangles, visualized by Gallyas silver staining, are reversed by 6 months of tau suppression. Most rTgTauEC animals develop silver-positive neurofibrillary tangles in the MEC by $18-21$ months of age. Transgene suppression from 21 to 24 months $(n=5)$ did not prevent Gallyas-positive neurons from accumulating; however, treatment for 6 months from 18 to 24 months $(n=5)$ both prevented new tangles and reversed existing tangles as there were no Gallyas-positive cells in any 24-month-old animals treated for 6 months with DOX ( $p=$ 0.0386). Images are labeled nontransgenic (NTG) and transgenic (TG). Scale bar, $100 \mu \mathrm{m}$. Results are expressed as the mean \pm SEM, ${ }^{*} p<0.05$.

ter would manifest in continued neuronal loss despite transgene suppression. To examine whether transgene suppression would affect ongoing neuronal loss, neuronal counts were performed on transgenic and control animals at 24 months of age treated with doxycycline either from 21 months of age for 3 months or from 18 months of age for 6 months, using stereological estimations of cresyl violet-labeled neuronal nuclei. In concert with the decrease in tau propagation, we observe a stabilization of neuron number in the EC after 6 months of doxycycline treatment (Fig. 7B), supporting the idea that NFTs are cleared rather than neurons that contained NFTs at 18 months of age degenerating during 6 months of transgene suppression.

\section{Discussion}

In this study, we used a mouse model that shows slow progression of tau aggregation and NFT formation starting in a subset of neurons in the EC-II and extending over time to the hippocampus and other fields. The model allows us to examine the natural history and consequences of existing NFTs on a synaptic neuronal circuit in isolation from the continued mutant human tau transgene expression. Our results suggest that (1) NFTs, even Gallyas-positive lesions, are reversible; (2) the axonal deafferen- tation/plasticity phenotype observed due to hippocampal deafferentation is reversible; (3) progressive synaptic and neuronal loss is stabilized. These results suggest an unexpected conclusion: many of the neural system consequences of tau overexpression, including aggregation, NFT formation and propagation, neuronal and synaptic deafferentation, can be reversed or stabilized by suppression of soluble human tau expression rather than being irreversible consequences of the formation of NFT. The latter conclusion is in accord with recent observations implicating soluble, nonfibrillar forms of tau in induction of caspases (SpiresJones et al., 2008; de Calignon et al., 2010) and mitochondrial mislocalization (Ebneth et al., 1998; Stamer et al., 2002; Stoothoff et al., 2009; Kopeikina et al., 2011; Matenia et al., 2012). Together, these results argue that stabilization and reversal of NFTassociated damage may be possible even in established disease when the lesions are already present.

We took advantage of the slowly progressive nature of the axonal lesions present in the rTgTauEC line to ask questions about the nature of chronic deafferentation and reinnervation of the perforant pathway zone. Sprouting of neighboring afferents is a compensatory plastic response thought to be an attempt to preserve synaptic inputs. Although most studies of lesioninduced plasticity use acute maximal lesions and relatively shortterm follow up, it has been noted in multiple settings that chronic reinnervation of deafferented brain structures can occur. For example, the pattern of sprouting of AChE fibers that is observed both after acute entorhinal or perforant pathway lesion in the rodent and nonhuman primate (Geddes et al., 1985; Hyman et al., 1987; Ihara, 1988; Deller and Frotscher, 1997; Shamy et al., 2007; Kadish and van Groen, 2009) is also observed in some AD patients, presumably due to the EC lesion-induced deafferentation of the hippocampus in AD (Geddes et al., 1985; Hyman et al., 1987). Our current data show that chronic slow deafferentation of the hippocampus results in a very similar process of induced plasticity in an experimental model as well.

In a related line (rTg4510) with more widespread expression in which the tau P301L transgene is driven by a CaMKII $\alpha$ promoter in the majority of pyramidal neurons in the brain, suppression of the transgene expression with doxycycline for 6 weeks led to an improvement in behavioral phenotype and an arrest of progression of neuronal loss, but NFTs continued to be present (Santacruz et al., 2005). The persistence of NFTs and tau aggregates in the rTg4510 mouse line after doxycycline treatment can be explained by both the short-term transgene suppression, for only 6 weeks, which led to diminished soluble tau but continued presence of aggregated tau. By contrast, our current data in the rTgTauEC reflect doxycycline suppression of transgene expression for prolonged periods - up to 6 months - suggesting that prolonged suppression of the tau transgene appears to lead to resolution of much of the fibrillar tau pathology. These crosssectional studies cannot unambiguously differentiate between the possibilities that tau aggregate containing neurons die in the ensuing 6 month period after the transgene is turned off, leading to a relative paucity of tangle-containing cells after 6 months of transgene suppression, or the possibility that the tau aggregates are actually slowly cleared in the absence of new synthesis of tau molecules. However, stereological assessment of neuron number in the EC showed that turning off transgene expression for 6 months resulted in stabilization of neuron numbers. Thus, it seems more likely that tangles are cleared rather than having a large number of tangle-bearing neurons die, because we do not detect ongoing additional neuronal loss after the transgene is suppressed. 

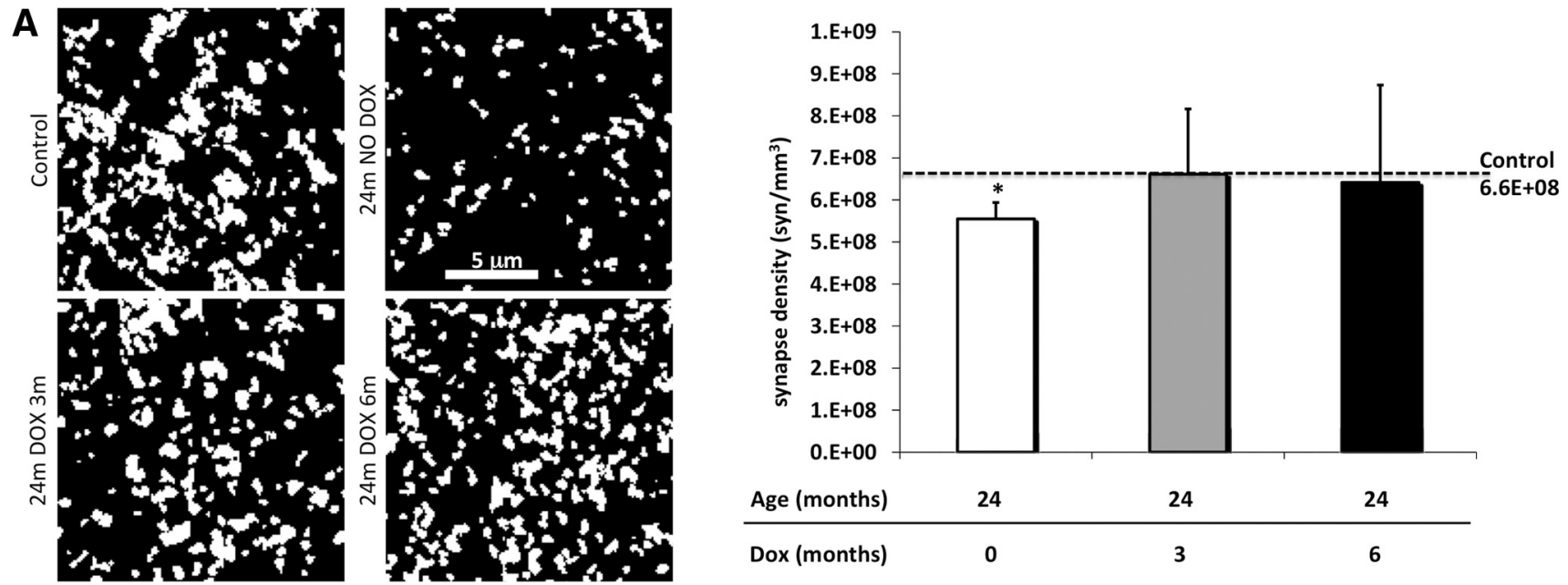

B
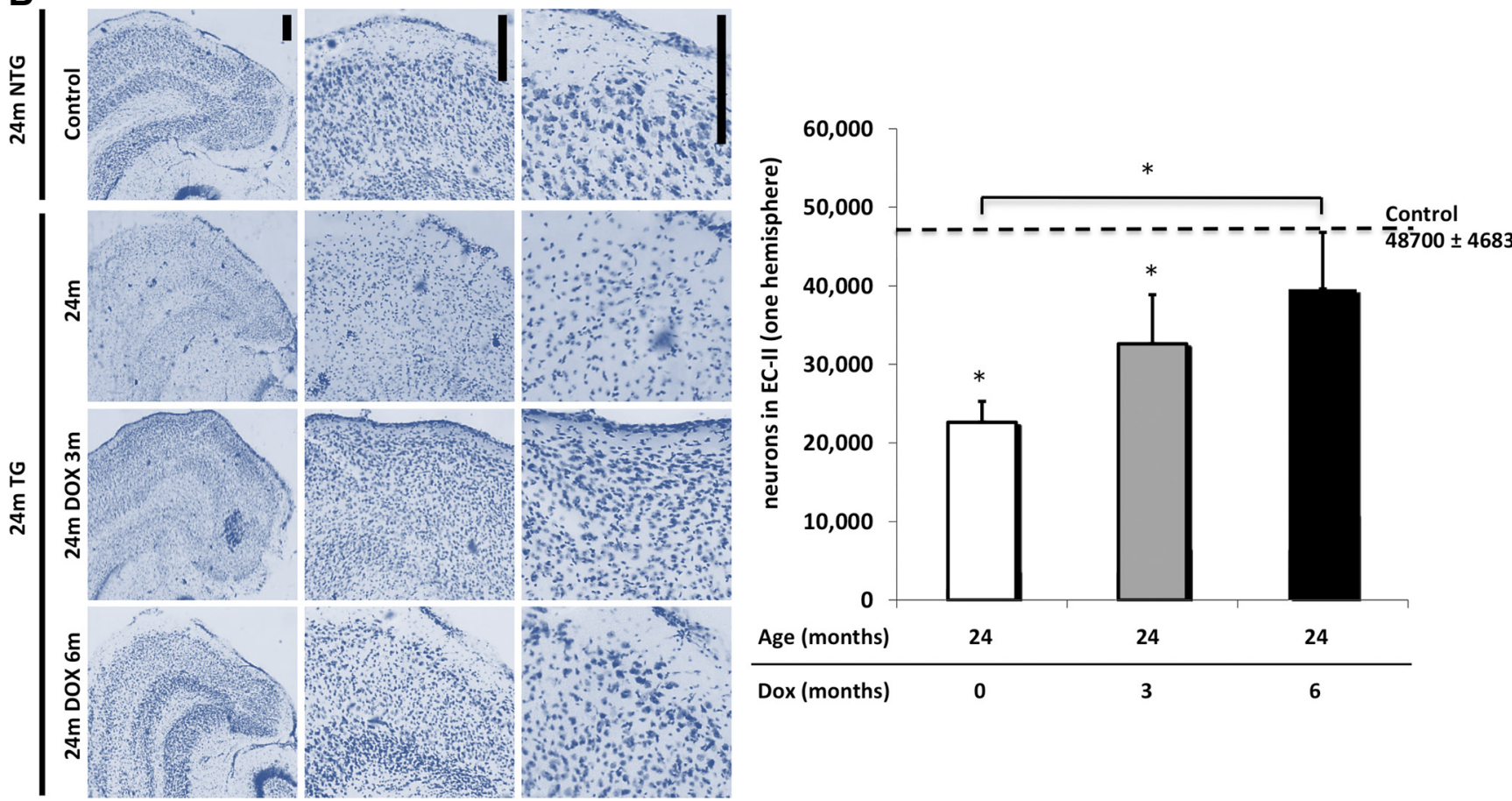

Figure 7. Synaptic loss in the target zone of the perforant pathway and neuronal loss in MEC can be prevented by doxycycline treatment. $A$, Array tomography using synaptophysin to label presynaptic structures in the middle molecular layer of the DG (scale bar, $5 \mu \mathrm{m}$ ) shows presynaptic loss at 24 months of age, indicating loss of synapses between EC-II neurons and DG neurons, which is prevented by 6 months of tau suppression $(p=0.0233)$. Images are maximum intensity projections of $15 \times 15 \mu \mathrm{m}$ regions of interest from 10 serial sections $(70 \mathrm{~nm}$ thickness) from processed output files showing objects counted as synapses. $\boldsymbol{B}$, Neuronal counts were performed on transgenic and control animals at 24 months of age treated with doxycycline starting either from 21 months of age for 3 months or from 18 months of age for 6 months, using stereological estimations of cresyl violet-labeled neuronal nuclei ( $n=5$ per group). rTgTauEC mice showed decreased neuronal counts at 24 months of age compared with controls $(p<0.0001)$, which is ameliorated by 3 months of tau suppression $(p=0.0499)$ and prevented by 6 months of transgene suppression ( $p=$ 0.0009). Representative images of cresyl violet labeled nuclei of the entorhinal cortex (EC) are shown on top; scale bar, $200 \mu \mathrm{m}$. There was partial recovery of neuronal loss in the EC after 6 months of doxycycline treatment. Results are expressed as the mean \pm SEM, ${ }^{*} p<0.05$.

The reversal of tangles is especially striking because assessment of tangles in this mouse model included not only immunostaining for human misfolded tau but also the robust NFT reagent Gallyas silver stain (de Calignon et al., 2012). Gallyaspositive NFTs are believed to be stable conformations of tau (Sun et al., 2002; Kertesz et al., 2005; Lee et al., 2010; Braak et al., 2011), and their apparent clearance leads to the conclusion that even highly aggregated tau inclusions can be cleared by neurons if the driving force of aggregation-in this case overexpression of P301L tau-is suppressed. Intriguingly, Gallyas-positive NFTs were completely cleared in some brains that still exhibited Alz50- and PHF1-positive lesions, implying that tangles may be cleared in the reverse order from which they were formed with silverpositive aggregates dissolving followed by hyperphosphorylated and misfolded forms of tau.

The mechanism whereby aggregated tau is cleared is unknown. Possibly, human tau soluble oligomeric species may impair the proteasome- or macroautophagy-mediated protein turn-over and degradation that have been implicated in tau clearance (Berger et al., 2007; Dickey et al., 2007; Carrettiero et al., 2009; Wang et al., 2009; Tai et al., 2012). We postulate that release of such clearance mechanisms from tau-based inhibition may 
allow slow but ultimately successful restoration of neuronal morphology. Alternatively, tau aggregates may not be a permanent accumulation of fibrillogenic proteins but rather a dynamic structure in a constant slow turnover. Although the clearance of tau in these studies makes lowering tau an attractive drug target in the treatment of neurodegeneration, the response of lesions in human tauopathy and the prevention of propagation by tau reduction has yet to be demonstrated as feasible.

In summary, turning off production of newly synthesized soluble tau is sufficient to prevent synapse and neuronal loss, reverse the transmission of tau to areas downstream from EC, and restore the normal pattern of $\mathrm{AChE}$ in a deafferented terminal zone. These observations also lead to several new questions: which pathways contribute to clearance of tau protein and of the abnormal tau aggregates? Which tau species are transmitted between neurons? Does the normalization of AChE staining after transgene suppression reflect also normalized function of the perforant pathway? Finally, extrapolation from this and other animal models suggest that caspase activation and cleavage of tau (Gamblin et al., 2003; Rissman et al., 2004; Spires-Jones et al., 2008; de Calignon et al., 2010), mitochondrial mislocalization (Ebneth et al., 1998; Stamer et al., 2002; Stoothoff et al., 2009; Kopeikina et al., 2011; Matenia et al., 2012), phospho- and aggregation-specific epitopes (Sydow et al., 2011a, b; Van der Jeugd et al., 2012), and even Gallyas-positive lesions can all be reversed by reduction of soluble tau expression. While there is presumably a "point of no return" after which neuronal death ensues, we postulate that some or all of these phenomena, long held to be end-stage pathology lesions in human $\mathrm{AD}$, may be at least in part amenable to therapeutic intervention as well.

\section{References}

Aubert I, Poirier J, Gauthier S, Quirion R (1994) Multiple cholinergic markers are unexpectedly not altered in the rat dentate gyrus following entorhinal cortex lesions. J Neurosci 14:2476-2484. Medline

Berger Z, Roder H, Hanna A, Carlson A, Rangachari V, Yue M, Wszolek Z, Ashe K, Knight J, Dickson D, Andorfer C, Rosenberry TL, Lewis J, Hutton M, Janus C (2007) Accumulation of pathological tau species and memory loss in a conditional model of tauopathy. J Neurosci 27:3650-3662. CrossRef Medline

Braak H, Braak E (1991) Neuropathological stageing of Alzheimer-related changes. Acta Neuropathol 82:239-259. CrossRef Medline

Braak H, Thal DR, Ghebremedhin E, Del Tredici K (2011) Stages of the pathologic process in Alzheimer disease: age categories from 1 to 100 years. J Neuropathol Exp Neurol 70:960-969. CrossRef Medline

Carrettiero DC, Hernandez I, Neveu P, Papagiannakopoulos T, Kosik KS (2009) The cochaperone BAG2 sweeps paired helical filament- insoluble tau from the microtubule. J Neurosci 29:2151-2161. CrossRef Medline

de Calignon A, Fox LM, Pitstick R, Carlson GA, Bacskai BJ, Spires-Jones TL, Hyman BT (2010) Caspase activation precedes and leads to tangles. Nature 464:1201-1204. CrossRef Medline

de Calignon A, Polydoro M, Suárez-Calvet M, William C, Adamowicz DH, Kopeikina KJ, Pitstick R, Sahara N, Ashe KH, Carlson GA, Spires-Jones TL, Hyman BT (2012) Propagation of tau pathology in a model of early Alzheimer's disease. Neuron 73:685-697. CrossRef Medline

Delacourte A, David JP, Sergeant N, Buée L, Wattez A, Vermersch P, Ghozali F, Fallet-Bianco C, Pasquier F, Lebert F, Petit H, Di Menza C (1999) The biochemical pathway of neurofibrillary degeneration in aging and Alzheimer's disease. Neurology 52:1158-1165. CrossRef Medline

Deller T, Frotscher M (1997) Lesion-induced plasticity of central neurons: sprouting of single fibres in the rat hippocampus after unilateral entorhinal cortex lesion. Prog Neurobiol 53:687-727. CrossRef Medline

Dickey CA, Kamal A, Lundgren K, Klosak N, Bailey RM, Dunmore J, Ash P, Shoraka S, Zlatkovic J, Eckman CB, Patterson C, Dickson DW, Nahman NS Jr, Hutton M, Burrows F, Petrucelli L (2007) The high-affinity HSP90-CHIP complex recognizes and selectively degrades phosphorylated tau client proteins. J Clin Invest 117:648-658. CrossRef Medline

Ebneth A, Godemann R, Stamer K, Illenberger S, Trinczek B, Mandelkow E
(1998) Overexpression of tau protein inhibits kinesin-dependent trafficking of vesicles, mitochondria, and endoplasmic reticulum: implications for Alzheimer's disease. J Cell Biol 143:777-794. CrossRef Medline

Gallyas F (1971) Silver staining of Alzheimer's neurofibrillary changes by means of physical development. Acta Morphol Acad Sci Hung 19:1-8. Medline

Gamblin TC, Chen F, Zambrano A, Abraha A, Lagalwar S, Guillozet AL, Lu M, Fu Y, Garcia-Sierra F, LaPointe N, Miller R, Berry RW, Binder LI, Cryns VL (2003) Caspase cleavage of tau: linking amyloid and neurofibrillary tangles in Alzheimer's disease. Proc Natl Acad Sci U S A 100:10032-10037. CrossRef Medline

Gatome CW, Slomianka L, Lipp HP, Amrein I (2010) Number estimates of neuronal phenotypes in layer II of the medial entorhinal cortex of rat and mouse. Neuroscience 170:156-165. CrossRef Medline

Geddes JW, Monaghan DT, Cotman CW, Lott IT, Kim RC, Chui HC (1985) Plasticity of hippocampal circuitry in Alzheimer's disease. Science 230: 1179-1181. CrossRef Medline

Geneser-Jensen FA, Blackstad TW (1971) Distribution of acetyl cholinesterase in the hippocampal region of the guinea pig. I. Entorhinal area, parasubiculum, and presubiculum. Z Zellforsch Mikrosk Anat 114:460 481. CrossRef Medline

Gómez-Isla T, Price JL, McKeel DW Jr, Morris JC, Growdon JH, Hyman BT (1996) Profound loss of layer II entorhinal cortex neurons occurs in very mild Alzheimer's disease. J Neurosci 16:4491-4500. Medline

Gossen M, Bujard H (1992) Tight control of gene expression in mammalian cells by tetracycline-responsive promoters. Proc Natl Acad Sci U S A 89: 5547-5551. CrossRef Medline

Harris JA, Koyama A, Maeda S, Ho K, Devidze N, Dubal DB, Yu GQ, Masliah E, Mucke L (2012) Human P301L-mutant tau expression in mouse entorhinal-hippocampal network causes tau aggregation and presynaptic pathology but no cognitive deficits. PLoS One 7:e45881. CrossRef Medline

Hyman BT, Van Hoesen GW, Damasio AR, Barnes CL (1984) Alzheimer's disease: cell-specific pathology isolates the hippocampal formation. Science 225:1168-1170. CrossRef Medline

Hyman BT, Kromer LJ, Van Hoesen GW (1987) Reinnervation of the hippocampal perforant pathway zone in Alzheimer's disease. Ann Neurol 21:259-267. CrossRef Medline

Ihara Y (1988) Massive somatodendritic sprouting of cortical neurons in Alzheimer's disease. Brain Res 459:138-144. CrossRef Medline

Kadish I, van Groen T (2009) Lesion-induced hippocampal plasticity in transgenic Alzheimer's disease mouse models: influences of age, genotype, and estrogen. J Alzheimers Dis 18:429-445. Medline

Kertesz A, McMonagle P, Blair M, Davidson W, Munoz DG (2005) The evolution and pathology of frontotemporal dementia. Brain 128:19962005. CrossRef Medline

Koffie RM, Meyer-Luehmann M, Hashimoto T, Adams KW, Mielke ML, Garcia-Alloza M, Micheva KD, Smith SJ, Kim ML, Lee VM, Hyman BT, Spires-Jones TL (2009) Oligomeric amyloid beta associates with postsynaptic densities and correlates with excitatory synapse loss near senile plaques. Proc Natl Acad Sci U S A 106:4012-4017. CrossRef Medline

Kopeikina KJ, Carlson GA, Pitstick R, Ludvigson AE, Peters A, Luebke JI, Koffie RM, Frosch MP, Hyman BT, Spires-Jones TL (2011) Tau accumulation causes mitochondrial distribution deficits in neurons in a mouse model of tauopathy and in human Alzheimer's disease brain. Am J Pathol 179:2071-2082. CrossRef Medline

Lee DC, Rizer J, Selenica ML, Reid P, Kraft C, Johnson A, Blair L, Gordon MN, Dickey CA, Morgan D (2010) LPS- induced inflammation exacerbates phospho-tau pathology in rTg4510 mice. J Neuroinflammation 7:56. CrossRef Medline

Levey AI, Wainer BH, Rye DB, Mufson EJ, Mesulam MM (1984) Choline acetyltransferase-immunoreactive neurons intrinsic to rodent cortex and distinction from acetylcholinesterase-positive neurons. Neuroscience 13: 341-353. CrossRef Medline

Li L, Tasic B, Micheva KD, Ivanov VM, Spletter ML, Smith SJ, Luo L (2010) Visualizing the distribution of synapses from individual neurons in the mouse brain. PLoS One 5:e11503. CrossRef Medline

Liu L, Drouet V, Wu JW, Witter MP, Small SA, Clelland C, Duff K (2012) Trans-synaptic spread of tau pathology in vivo. PLoS One 7:e31302. CrossRef Medline

Lynch GS, Lucas PA, Deadwyler SA (1972) The demonstration of acetylcho- 
linesterase containing neurones within the caudate nucleus of the rat. Brain Res 45:617-621. CrossRef Medline

Matenia D, Hempp C, Timm T, Eikhof A, Mandelkow EM (2012) Microtubule affinity-regulating kinase 2 (MARK2) turns on phosphatase and tensin homolog (PTEN)-induced kinase 1 (PINK1) at Thr-313, a mutation site in Parkinson disease: effects on mitochondrial transport. J Biol Chem 287:8174-8186. CrossRef Medline

Mesulam MM, Geula C (1991) Acetylcholinesterase-rich neurons of the human cerebral cortex: cytoarchitectonic and ontogenetic patterns of distribution. J Comp Neurol 306:193-220. CrossRef Medline

Micheva KD, Smith SJ (2007) Array tomography: a new tool for imaging the molecular architecture and ultrastructure of neural circuits. Neuron 55: 25-36. CrossRef Medline

Miyamichi K, Amat F, Moussavi F, Wang C, Wickersham I, Wall NR, Taniguchi H, Tasic B, Huang ZJ, He Z, Callaway EM, Horowitz MA, Luo L (2011) Cortical representations of olfactory input by trans-synaptic tracing. Nature 472:191-196. Medline

Rissman RA, Poon WW, Blurton-Jones M, Oddo S, Torp R, Vitek MP, LaFerla FM, Rohn TT, Cotman CW (2004) Caspase-cleavage of tau is an early event in Alzheimer disease tangle pathology. J Clin Invest 114:121-130. CrossRef Medline

Santacruz K, Lewis J, Spires T, Paulson J, Kotilinek L, Ingelsson M, Guimaraes A, DeTure M, Ramsden M, McGowan E, Forster C, Yue M, Orne J, Janus C, Mariash A, Kuskowski M, Hyman B, Hutton M, Ashe KH (2005) Tau suppression in a neurodegenerative mouse model improves memory function. Science 309:476-481. CrossRef Medline

Shamy JL, Buckmaster CA, Amaral DG, Calhoun ME, Rapp PR (2007) Reactive plasticity in the dentate gyrus following bilateral entorhinal cortex lesions in cynomolgus monkeys. J Comp Neurol 502:192-201. CrossRef Medline

Spires TL, Orne JD, SantaCruz K, Pitstick R, Carlson GA, Ashe KH, Hyman BT (2006) Region-specific dissociation of neuronal loss and neurofibrillary pathology in a mouse model of tauopathy. Am J Pathol 168:1598-1607. CrossRef Medline

Spires-Jones TL, de Calignon A, Matsui T, Zehr C, Pitstick R, Wu HY, Osetek JD, Jones PB, Bacskai BJ, Feany MB, Carlson GA, Ashe KH, Lewis J, Hyman BT (2008) In vivo imaging reveals dissociation between caspase activation and acute neuronal death in tangle-bearing neurons. J Neurosci 28:862-867. CrossRef Medline

Stamer K, Vogel R, Thies E, Mandelkow E, Mandelkow EM (2002) Tau blocks traffic of organelles, neurofilaments, and APP vesicles in neurons and enhances oxidative stress. J Cell Biol 156:1051-1063. CrossRef Medline

Stoothoff W, Jones PB, Spires-Jones TL, Joyner D, Chhabra E, Bercury K, Fan Z, Xie H, Bacskai B, Edd J, Irimia D, Hyman BT (2009) Differential effect of three-repeat and four-repeat tau on mitochondrial axonal transport. J Neurochem 111:417-427. CrossRef Medline

Sun A, Nguyen XV, Bing G (2002) Comparative analysis of an improved thioflavin-s stain, Gallyas silver stain, and immunohistochemistry for neurofibrillary tangle demonstration on the same sections. J Histochem Cytochem 50:463-472. CrossRef Medline

Sydow A, Van der Jeugd A, Zheng F, Ahmed T, Balschun D, Petrova O, Drexler D, Zhou L, Rune G, Mandelkow E, D’Hooge R, Alzheimer C, Mandelkow EM (2011a) Reversibility of Tau-related cognitive defects in a regulatable FTD mouse model. J Mol Neurosci 45:432-437. CrossRef Medline

Sydow A, Van der Jeugd A, Zheng F, Ahmed T, Balschun D, Petrova O, Drexler D, Zhou L, Rune G, Mandelkow E, D’Hooge R, Alzheimer C, Mandelkow EM (2011b) Tau-induced defects in synaptic plasticity, learning, and memory are reversible in transgenic mice after switching off the toxic Tau mutant. J Neurosci 31:2511-2525. CrossRef Medline

Tai HC, Serrano-Pozo A, Hashimoto T, Frosch MP, Spires-Jones TL, Hyman BT (2012) The synaptic accumulation of hyperphosphorylated tau oligomers in Alzheimer disease is associated with dysfunction of the ubiquitin-proteasome system. Am J Pathol 181:1426-1435. CrossRef Medline

Van der Jeugd A, Hochgräfe K, Ahmed T, Decker JM, Sydow A, Hofmann A, Wu D, Messing L, Balschun D, D'Hooge R, Mandelkow EM (2012) Cognitive defects are reversible in inducible mice expressing proaggregant full-length human Tau. Acta Neuropathol 123:787-805. CrossRef Medline

van Groen T (2001) Entorhinal cortex of the mouse: cytoarchitectonical organization. Hippocampus 11:397-407. CrossRef Medline

Wang Y, Martinez-Vicente M, Krüger U, Kaushik S, Wong E, Mandelkow EM, Cuervo AM, Mandelkow E (2009) Tau fragmentation, aggregation and clearance: the dual role of lysosomal processing. Hum Mol Genet 18:4153-4170. CrossRef Medline

Witter MP (2007) The perforant path: projections from the entorhinal cortex to the dentate gyrus. Prog Brain Res 163:43-61. CrossRef Medline

Yasuda M, Mayford MR (2006) CaMKII activation in the entorhinal cortex disrupts previously encoded spatial memory. Neuron 50:309-318. CrossRef Medline 